DOI: https://doi.org/10.47405/mjssh.v6i7.857

\begin{tabular}{|c|c|}
\hline 4 & Malaysian Journal of Social Sciences and Humanities (MJSSH) \\
\hline $\begin{array}{l}\text { Malaysian Journa of } \\
\text { Social cciences and }\end{array}$ & Volume 6, Issue 7, July 2021 \\
\hline (MJ-sSH) & e-ISSN : 2504-8562 \\
\hline & $\begin{array}{l}\text { Journal home page: } \\
\text { www.msocialsciences.com }\end{array}$ \\
\hline
\end{tabular}

\title{
Hubungan antara Emosi Ibu Bapa dengan Kanak-kanak dan Kepentingannya Terhadap Perkembangan Awal Kanak-kanak
}

\author{
Khairun Nisa Binti Md Isa ${ }^{1}$, Kamariah Abu Bakar' ${ }^{1}$ \\ ${ }^{1}$ Fakulti Pendidikan, Universiti Kebangsaan Malaysia (UKM) \\ Correspondence: Kamariah Abu Bakar (kamariah_abubakar@ukm.edu.my)
}

\begin{abstract}
Abstrak
Setiap perkembangan kanak-kanak yang berlaku perlu diambil perhatian dari pelbagai aspek oleh kedua ibu bapa mahupun setiap orang yang terdekat dengan kanak-kanak tersebut. Perasaan yang mengikat kita dengan orang-orang penting dalam hidup kita sering disebut dan dikenali sebagai 'ikatan emosi'. Kegagalan dalam perkembangan kanak-kanak itu sebenarnya akan menjejaskan masa hadapan mereka. Kanak-kanak mula mengembangkan emosi mereka semasa peringkat bayi, yang berlangsung kira-kira sejak lahir hingga usia dua tahun. Kajian ini dijalankan untuk mengenal pasti hubungan di antara emosi ibu bapa dengan kanak-kanak dan kepentingannya terhadap perkembangan awal kanakkanak. Dapatan kajian menunjukkan bahawa faktor ibu bapa mempunyai hubungan yang signifikan terhadap perkembangan emosi kanak-kanak. Faktor yang dikenal pasti menyumbang kepada perkembangan kanak-kanak adalah termasuk dengan peranan dan gaya keibubapaan. Kesimpulannya terdapat hubung kait antara emosi ibu bapa dengan perkembangan awal kanak-kanak.
\end{abstract}

Kata kunci: emosi ibu bapa, kanak-kanak, perkembangan awal kanak-kanak

\section{The Relationship Between Parental Emotions with Children in The Importance of Early Childhood Development}

\begin{abstract}
The feelings that bind us to the important people in our lives are often referred to and known as 'emotional bonds.' Failure in the child's development will actually affect their future. Children begin to develop their emotions during the infant stage, which lasts approximately from birth to the age of two years. This study was conducted to identify the relationship between parental emotions with children and its importance to early childhood development. The findings of the study indicate that parental factors have a significant relationship to children's emotional development. Factors identified as contributing to a child's development include with the role and style of parenting. In conclusion there is a correlation between parental emotions and early child development.
\end{abstract}

Keywords: emotions of parents, children, early childhood development 


\section{Pengenalan}

Ikatan emosi adalah perasaan yang lahir untuk mengikat kita dengan orang-orang yang penting dalam hidup kita. Dimana ianya memainkan peranan yang penting di dalam tumbesaran anak-anak. Oleh itu, adalah mustahak untuk memikirkan ibu bapa berhubung dengan anak-anak dan juga anak-anak berhubung dengan ibu bapa. Apabila kanak-kanak secara emosional terikat dengan komuniti individu yang menjaga mereka, mereka mendapat sokongan berharga yang menolong mereka tumbuh dan berkembang. Melalui pengembaraan dan hubungan ikatan mereka, mereka belajar tentang betul dan salah. Mereka belajar mentafsirkan pelbagai pengalaman (Ainsworth, 2008).

Anak-anak belajar kemahiran sosial yang menolong mereka mengekalkan hubungan yang ada dan mengembangkan yang baru. Anak-anak akan belajar untuk berdikari dan bekerja dengan baik dengan orang lain. Singkatnya, mereka mengembangkan pelbagai kemahiran yang tidak mudah dipelajari melalui arahan langsung. Pelajaran sosial dan emosi paling baik dipelajari melalui hubungan. Penerimaan minat anak dengan tindak balas yang cepat bergantung kepada isyarat kanak-kanak bagi menyokong pembelajaran dengan memfasilitasi perkembangan mekanisme untuk mengatasi tekanan dan kebaharuan di persekitarannya. Oleh itu, ibu bapa merupakan elemen yang terpenting dalam tumbesaran emosi dan perkembangan awal kanak-kanak. Pada masa kini, kita dapat melihat pendidikan awal bagi kanak-kanak kurang diamalkan di rumah. Sedangkan keterlibatan ibu bapa dalam membantu perkembangan awal anak-anak itu amatlah penting (Green, 2007).

Dalam hal ini, penting untuk mengisi jurang pengetahuan mengenai jenis tingkah laku ibu bapa yang mempengaruhi perkembangan emosi anak-anak mereka, dan dengan cara apa. Penting untuk meneroka bagaimana tingkah laku ibu bapa yang positif dan negatif mempengaruhi perkembangan emosi anakanak. Seperti yang dinyatakan oleh Fincham (2001), "Ini adalah waktu yang sangat tepat untuk memeriksa status lapangan saat ini dan merenungkan arah masa depan" Dalam penyelidikan khusus ini, akan diterokai sama ada dan bagaimana konflik antara ibu bapa mempengaruhi keselamatan emosi dan perkembangan anak-anak mereka (Fagan, 2003).

\section{Objektif Kajian}

Objektif kajian ini adalah untuk mengkaji faktor yang menyumbang kepada perkembangan awal kanak-kanak, mengenal pasti hubung kait emosi kanak-kanak dengan perkembangan awal kanak-kanak dan memberi kepastian bahawa ibu bapa merupakan elemen penting dalam perkembangan awal kanakkanak.

\section{Sorotan Literatur}

Setiap perkembangan kanak-kanak yang berlaku perlu diambil perhatian dari pelbagai aspek oleh kedua ibu bapa mahupun setiap orang yang terdekat dengan kanak-kanak tersebut. Jika emosi kedua ibu bapa tidak dapat dikawal dan sering dilihat oleh kanak-kanak yang sedang membesar, hal ini akan mengganggu perkembangan kanak-kanak tersebut. Bagi ibu bapa yang inginkan perkembangan potensi kanak-kanak secara meluas, kanak-kanak tersebut perlulah terdedah dengan persekitaran yang baik. Menurut kajian lepas Bobrow (2019), jika masalah tingkah laku yang sering dilakukan oleh kanakkanak ini tidak dibendung, hal ini akan memberi kesan terhadap kes jenayah jika mereka sudah meningkat remaja atau dewasa kelak. Terdapat pelbagai faktor yang memainkan peranan penting dalam pembentukan tingkah laku kanak-kanak. Saadah et al. (2017) menyatakan bahawa salah satu faktor yang menyumbang kepada masalah tingkah laku kanak-kanak adalah disebabkan faktor institusi sosial iaitu keluarga seperti kurangnya didikan dan perhatian ibu bapa. Apabila kanak-kanak tersebut mempunyai emosi yang terkawal dan stabil, ini akan menyebabkan kanak-kanak tersebut lebih yakin dalam perhubungan serta mudah untuk berinteraksi dengan orang lain. 


\section{Gaya Keibubapaan}

Seperti yang dinyatakan oleh Baumrind (1971), gaya keibubapaan memberikan penunjuk yang kuat terhadap fungsi keibubapaan yang meramalkan kesejahteraan anak di sebilangan spektrum persekitaran dan pelbagai komuniti anak-anak. Gaya keibubapaan merujuk kepada gaya asuhan yang dipraktiskan untuk mendidik anak-anak. Ianya turut meliputi interaksi ibu bapa-anak, aktiviti bersama ibu bapaanak, penglibatan ibu bapa dalam pendidikan anak-anak adalah penting dalam sosialisasi dan fungsi anak-anak. Menurut kajian Azizi Yahaya (2013), faktor keluarga merupakan penyumbang penting kepada proses perkembangan kanak-kanak bagi menentukan sikap, nilai dan sistem kepercayaan diterapkan dalam minda kanak-kanak serta menjadi medan kepada proses perkembangan emosi, kognitif dan sosial setiap ahli dalam institusi tersebut keluarga tersebut. Kajian beliau menyarankan pemantapan institusi keluarga sebagai jalan penyelesaian untuk membentuk perkembangan yang positif dalam diri kanak-kanak. Ianya meliputi perkembangan emosi, kognitif dan sosial. Ibu bapa merupakan orang yang bertanggungjawab untuk mencorakkan masa hadapan kehidupan anak-anak mereka. Mereka tidak boleh menyerahkan proses pendidikan anak-anak kepada guru mahupun pengasuh. Perlu diingati, seorang guru mahupun pengasuh hanya berperanan untuk membantu dalam menjaga dan mendidik anak-anak berikutan oleh ibu bapa mempunyai tanggungjawab untuk bekerja.

\section{Kecerdasan Emosi}

Menurut Goleman (1999), kecerdasan emosi adalah kebolehan individu menyedari, mengenal pasti dan mengurus emosinya sendiri serta mampu menjalin hubungan mesra dengan orang lain serta memiliki motivasi kendiri yang tinggi. Kesedaran emosi berkait rapat dengan bagaimana seseorang sedar akan proses-proses yang berlaku (Rieffe et al., 2008) semasa sesuatu emosi yang berlaku. Selain itu, kesedaran emosi juga berkait rapat dengan emotional intelligence (EI) seseorang (Ciarrochi, Chan \& Bajgar, 2000). Kajian Ciarrochi, Chan dan Bajgar (2000) juga mendapati bahawa self-report measure of emotional intelligence (SEI), atau kesedaran emosi boleh diukur dalam kalangan ibu bapa sepanjang proses mendidik anak-anak. Ianya bermula semasa peringkat bayi lagi iaitu seawal usia kelahiran hingga dua tahun. Anak lahirnya seperti sehelai kanvas putih dan ibu bapalah yang mencorak kanvas itu dengan pelbagai warna. Dalam mencorakkan peribadi anak-anak, ianya bermula dari pendidikan seawal usia kanak-kanak hasil didikan daripada ibu bapa. Di peringkat ini, banyak pembelajaran awal berlaku pada kanak-kanak. Sebilangan besar pembelajaran ini berlaku melalui interaksi dengan ibu bapa dan pemerhatian hubungan ibu bapa, yang merupakan tokoh pertama dan paling menonjol dalam kehidupan awal anak.

Alina Turcule \& Cristina Tulbure (2015) menyatakan bahawa peluang pertama untuk membangunkan elemen-elemen kecerdasan emosi adalah semasa kanak-kanak itu di awal perkembangan mereka dan keupayaan ini akan terus berkembang sepanjang mendapat pendidikan di sekolah. Ibu bapa juga perlu menjadi pendengar kepada anak mereka kerana sesetengah kanak-kanak yang beremosi akan meningkat lagi emosi apabila perasaan atau luahan mereka disekat (Naimah et al., 2018). Menurut kajian lepas, ibu bapa yang berjaya dalam mengajar anak mereka untuk mengenali emosi masingmasing serta dapat mengendalikan emosi dengan sebaik mungkin adalah ibu bapa yang telah menguasai atau mendalami ilmu keibubapaan. Ilmu tersebut amat penting kerana jika ibu bapa tidak tahu kaedah dan cara untuk mengendalikan kanak-kanak pada usia awal, hal ini akan menyebabkan kanak-kanak tersebut mungkin cepat terpengaruh terhadap benda yang negatif oleh rakan sebaya.

Hoover-Dempsey dan Sandler (1995) pula menyatakan bahawa emosi ibu bapa dalam perkembangan dan tumbesaran anak mampu memberikan kesan yang positif kepada pendidikan anak-anak. Akhir sekali, Saiti dan Mitrosili (2005) menyatakan bahawa penglibatan ibu bapa dalam pendidikan anak mempunyai pengaruh yang penting ke atas perkembangan anak-anak dari segi pendidikan dan pembangunan kendiri yang berkaitan. Hal ini kerana apabila ibu bapa menunjukkan reaksi yang positif mengenai pendidikan anak, secara langsung anak-anak tersebut akan lebih menyukai hal-hal yang melibatkan pendidikan kerana ibu bapa mereka mengambil berat mengenai pendidikan mereka. 


\section{Metod Kajian}

Kajian ini melibatkan 100 buah keluarga yang terdiri dari 50 orang ibu bekerja sepenuh masa dan 50 orang bapa bekerja sepenuh masa. Sampel kajian terdiri tertumpu kepada keluarga berpendapatan di bawah RM 4000 (di bawah B40). Kajian ini menggunakan soal selidik Tingkah Laku Kanak-kanak (CBCL) yang merangkumi aspek untuk menilai kecekapan dan masalah tingkah laku afektif. CBCL adalah instrumen dari Achenbach System of Empirically Based Assessment (ASEBA). Instrumen ini mengatur dua masalah tingkah laku jalur lebar, gejala dalaman dan luaran berdasarkan jumlah skor $\mathrm{T}$. Kanak-kanak dengan skor CBCL T 63 atau ke atas untuk salah satu tingkah laku dalaman atau luaran atau kedua-duanya, dianggap berisiko klinikal. Soal selidik diedarkan kepada ibu bapa yang telah terpilih sebagai responden. Para responden diberikan penerangan yang teliti dan masa secukupnya bagi menjawab borang soal selidik ini. Segala maklumat yang diberikan responden dirahsiakan dan bertujuan untuk kajian sahaja. Semua soal selidik yang telah diisi dikutip selepas dua minggu.

\section{Hasil Kajian}

\section{Emosi ibu bapa dalam perkembangan awal kanak-kanak}

Menurut Goleman (1999), kecerdasan emosi adalah kebolehan individu menyedari, mengenal pasti dan mengurus emosinya sendiri serta mampu menjalin hubungan mesra dengan orang lain serta memiliki motivasi kendiri yang tinggi. Pandangan ini selari dengan pendapat Mayer, Caruso dan Salovey (1999) bahawa kecerdasan emosi adalah kemampuan individu mengenal pasti makna-makna emosi dan perkaitannya dengan perkara-perkara lain, serta kebolehan menaakul dan menyelesaikan masalah.

Jadual 1: Emosi ibu bapa dalam perkembangan awal kanak-kanak

\begin{tabular}{|c|c|c|c|c|c|c|c|}
\hline Pernyataan & STS & TS & $\mathbf{N}$ & $\mathbf{S}$ & SS & Min & SP \\
\hline $\begin{array}{l}\text { Perkembangan awal kanak-kanak } \\
\text { sangat penting kepada ibu bapa }\end{array}$ & $\begin{array}{l}0 \\
(0 \%)\end{array}$ & $\begin{array}{l}0 \\
(0 \%)\end{array}$ & $\begin{array}{l}0 \\
(0 \%)\end{array}$ & $\begin{array}{l}3 \\
(3 \%)\end{array}$ & $\begin{array}{l}97 \\
(97 \%)\end{array}$ & 4.97 & 0.171 \\
\hline $\begin{array}{l}\text { Ibu bapa merupakan faktor yang } \\
\text { penting kepada perkembangan } \\
\text { anak-anak }\end{array}$ & $\begin{array}{l}0 \\
(0 \%)\end{array}$ & $\begin{array}{l}0 \\
(0 \%)\end{array}$ & $\begin{array}{l}0 \\
(0 \%)\end{array}$ & $\begin{array}{l}5 \\
(5 \%)\end{array}$ & $\begin{array}{l}95 \\
(95 \%)\end{array}$ & 4.95 & 0.219 \\
\hline $\begin{array}{l}\text { Emosi kedua ibu bapa akan } \\
\text { memberi kesan yang buruk } \\
\text { terhadap perkembangan awal } \\
\text { kanak-kanak }\end{array}$ & $\begin{array}{l}0 \\
(0 \%)\end{array}$ & $\begin{array}{l}0 \\
(0 \%)\end{array}$ & $\begin{array}{l}1 \\
(1 \%)\end{array}$ & $\begin{array}{l}9 \\
(9 \%)\end{array}$ & $\begin{array}{l}90 \\
(90 \%)\end{array}$ & 4.89 & 0.345 \\
\hline $\begin{array}{l}\text { Dengan menunjukkan contoh } \\
\text { pengawalan emosi kepada kanak- } \\
\text { kanak, hal ini akan memberi kesan } \\
\text { yang positif } \\
\text { kepada kanak-kanak tersebut }\end{array}$ & $\begin{array}{l}0 \\
(0 \%)\end{array}$ & $\begin{array}{l}0 \\
(0 \%)\end{array}$ & $\begin{array}{l}2 \\
(2 \%)\end{array}$ & $\begin{array}{l}6 \\
(6 \%)\end{array}$ & $\begin{array}{l}92 \\
(92 \%)\end{array}$ & 4.9 & 0.362 \\
\hline $\begin{array}{ll}\text { Ibu bapa yang kurang mahir dalam } \\
\text { pendidikan awal kanak-kanak akan } \\
\text { gagal dalam } & \text { memastikan } \\
\text { perkembangan } & \\
\text { awal kanak-kanak } & \text { berkembang } \\
\text { dengan baik } & \end{array}$ & $\begin{array}{l}1 \\
(1 \%)\end{array}$ & $\begin{array}{l}5 \\
(5 \%)\end{array}$ & $\begin{array}{l}11 \\
(11 \%\end{array}$ & $\begin{array}{l}21 \\
(21 \% \\
)\end{array}$ & $\begin{array}{l}62 \\
(62 \%)\end{array}$ & 4.38 & 0.94 \\
\hline Keseluruhan & & & & & & 4.818 & 0.282 \\
\hline
\end{tabular}


Menurut Goleman (1999), kecerdasan emosi adalah kebolehan individu menyedari, mengenal pasti dan mengurus emosinya sendiri serta mampu menjalin hubungan mesra dengan orang lain serta memiliki motivasi kendiri yang tinggi. Hasil dapatan kajian juga menunjukkan bahawa, "Perkembangan awal kanak-kanak sangat penting kepada ibu bapa" mencatatkan min yang tertinggi ( $\min =4.97, \mathrm{SP}=1.171)$ dan "Ibu bapa yang kurang mahir dalam pendidikan awal kanak-kanak akan gagal dalam memastikan perkembangan awal kanak-kanak berkembang dengan baik" mencatatkan min yang terendah (min= 4.38, $\mathrm{SP}=0.94)$.

\section{Faktor yang menyumbang kepada perkembangan anak-anak}

Kepentingan proses keluarga dalam perkembangan anak telah lama disarankan oleh ahli psikologi. Ahli-ahli psikologi ini menunjukkan bahawa gaya keibubapaan yang merangkumi interaksi ibu bapaanak, aktiviti bersama ibu bapa-anak, penglibatan ibu bapa dalam pendidikan anak-anak adalah penting dalam sosialisasi dan fungsi anak-anak. Rubin dan Clark (1983) bersetuju bahawa kanak-kanak yang terlibat dengan peraturan dan bersosial semasa bermain cenderung untuk menjadi orang yang paling popular dalam kumpulannya dan seterusnya lebih berjaya dalam kemahiran sosial mereka.

Jadual 2: Faktor yang menyumbang kepada perkembangan anak-anak

\begin{tabular}{|c|c|c|c|c|c|c|c|}
\hline Pernyataan & STS & TS & $\mathbf{N}$ & $\mathbf{S}$ & SS & Min & SP \\
\hline $\begin{array}{l}\text { Faktor peribadi dan faktor sosial } \\
\text { akan mengganggu perkembangan } \\
\text { awal kanak-kanak }\end{array}$ & $\begin{array}{l}0 \\
(0 \%)\end{array}$ & $\begin{array}{l}0 \\
(0 \%)\end{array}$ & $\begin{array}{l}6 \\
(6 \%)\end{array}$ & $\begin{array}{l}17 \\
(17 \%)\end{array}$ & $\begin{array}{l}77 \\
(77 \%)\end{array}$ & 4.71 & 0.573 \\
\hline $\begin{array}{l}\text { Ahli keluarga berperanan penting } \\
\text { dan menjadi petunjuk arah kepada } \\
\text { perkembangan } \\
\text { tersebut }\end{array}$ & $\begin{array}{l}0 \\
(0 \%)\end{array}$ & $\begin{array}{l}0 \\
(0 \%)\end{array}$ & $\begin{array}{l}3 \\
(3 \%)\end{array}$ & $\begin{array}{l}12 \\
(12 \%)\end{array}$ & $\begin{array}{l}85 \\
(85 \%)\end{array}$ & 4.82 & 0.457 \\
\hline $\begin{array}{l}\text { Apabila ahli keluarga menunjukkan } \\
\text { contoh yang tidak baik } \\
\text { berkemungkinan } \\
\text { perkembangan kanak-kanak } \\
\text { tersebut juga akan negative }\end{array}$ & $\begin{array}{l}0 \\
(0 \%)\end{array}$ & $\begin{array}{l}1 \\
(1 \%)\end{array}$ & $\begin{array}{l}1 \\
(1 \%)\end{array}$ & $\begin{array}{l}13 \\
(13 \%)\end{array}$ & $\begin{array}{l}85 \\
(85 \%)\end{array}$ & 4.82 & 0.479 \\
\hline $\begin{array}{l}\text { Rakan sebaya merupakan salah } \\
\text { satu faktor yang mempengaruhi } \\
\text { perkembangan kanak-kanak }\end{array}$ & $\begin{array}{l}0 \\
(0 \%)\end{array}$ & $\begin{array}{l}3 \\
(3 \%)\end{array}$ & $\begin{array}{l}7 \\
(7 \%)\end{array}$ & $\begin{array}{l}13 \\
(13 \%)\end{array}$ & $\begin{array}{l}77 \\
(77 \%)\end{array}$ & 4.64 & 0.745 \\
\hline $\begin{array}{l}\text { Apabila rakan tersebut bersikap } \\
\text { negatif berkemungkinan kanak- } \\
\text { kanak juga turut bersikap negative }\end{array}$ & $\begin{array}{l}0 \\
(0 \%)\end{array}$ & $\begin{array}{l}3 \\
(3 \%)\end{array}$ & $\begin{array}{l}9 \\
(9 \%)\end{array}$ & $\begin{array}{l}15 \\
(15 \%)\end{array}$ & $\begin{array}{l}73 \\
(73 \%)\end{array}$ & 4.58 & 0.78 \\
\hline $\begin{array}{l}\text { Apabila guru memberikan } \\
\text { pengajaran dan pembelajaran yang } \\
\text { berkesan, berkemungkinan akan } \\
\text { menyebabkan kanak-kanak tersebut } \\
\text { turut } \\
\text { seorang yang positif }\end{array}$ & $\begin{array}{l}0 \\
(0 \%)\end{array}$ & $\begin{array}{l}0 \\
(0 \%)\end{array}$ & $\begin{array}{l}2 \\
(2 \%)\end{array}$ & $\begin{array}{l}13 \\
(13 \%)\end{array}$ & $\begin{array}{l}85 \\
(85 \%)\end{array}$ & 4.83 & 0.427 \\
\hline $\begin{array}{l}\text { Ibu bapa perlu mengawal emosi } \\
\text { mereka dengan sebaik mungkin } \\
\text { bagi memastikan perkembangan } \\
\text { anak mereka tidak terjejas }\end{array}$ & $\begin{array}{l}0 \\
(0 \%)\end{array}$ & $\begin{array}{l}0 \\
(0 \%)\end{array}$ & $\begin{array}{l}1 \\
(1 \%)\end{array}$ & $\begin{array}{l}7 \\
(7 \%)\end{array}$ & $\begin{array}{l}92 \\
(92 \%)\end{array}$ & 4.91 & 0.32 \\
\hline
\end{tabular}


Kes penceraian kedua ibu bapa dapat memberi kesan yang negatif terhadap perkembangan awal kanak-kanak $(1 \%)$ $(1 \%)$ $(6 \%)$ 16 $(16 \%)$ $(76 \%)$ 4.65 0.729 4.74 5 0.412

Keseluruhan

Berdasarkan nilai peratus yang tertinggi adalah responden memilih sangat setuju apabila ibu bapa perlu mengawal emosi mereka dengan sebaik mungkin bagi memastikan perkembangan anak mereka tidak terjejas (92\%). Dalam mencorakkan kehidupan anak-anak, asuhan, didikan, status ekonomi memberi kesan kepada perkembangan mereka. Sebagai contoh, kanak-kanak yang dilahirkan dalam sebuah rumah yang mesra dan penuh dengan kasih sayang akan mengalami perkembangan emosi yang sihat. Ini diikuti dengan ahli keluarga berperanan penting dan menjadi petunjuk arah kepada perkembangan anak-anak, ahli keluarga yang menunjukkan contoh yang tidak baik berkemungkinan perkembangan anak-anak akan negatif dan apabila guru memberikan pengajaran dan pembelajaran yang berkesan menyebabkan kanak-kanak menjadi positif $(85 \%)$. Untuk tujuan itu, ibu bapa harus mempraktikkan gaya keibubapaan yang berkesan dalam mendidik anak-anak. Gaya keibubapaan merujuk kepada gaya asuhan yang dipraktikkan untuk mendidik anak-anak. Ibu bapa perlu mengawal emosi mereka dengan sebaik mungkin bagi memastikan perkembangan anak mereka tidak terjejas" mencatatkan min yang tertinggi ( $\mathrm{min}=4.91, \mathrm{SP}=0.32)$ dan "Apabila rakan tersebut bersikap negatif berkemungkinan kanakkanak juga turut bersikap negatif" mencatatkan min yang terendah $(\min =4.58, \mathrm{SP}=0.78)$. Berpandukan kepada dapatan hasil kajian, secara keseluruhannya menunjukkan bahawa responden bersetuju terhadap faktor yang menyumbang kepada perkembangan anak-anak $(\min =4.745, \mathrm{SP}=0.412)$

\section{Hubung kait emosi kanak-kanak dengan perkembangan}

Berdasarkan keputusan yang diperoleh menunjukkan bahawa terdapat hubung kait yang antara emosi kanak-kanak dengan perkembangan $(r=0.688 \mathrm{n}=100 \mathrm{p}=0.000)$. Ianya dikaitkan dengan perkembangan emosi mereka yang bermula seawal peringkat bayi. Banyak pembelajaran awal berlaku untuk anak, mengenai persekitaran umum mereka dan orang-orang yang berada di dalamnya (Cherry, 2015). Rentetan itu, emosi yang ditonjolkan memberi impak kepada perkembangan mereka.

Jadual 3: Hubung kait emosi kanak-kanak dengan perkembangan

\begin{tabular}{lll}
\hline & Perkembangan & \\
\hline & $\mathrm{R}$ & Sig \\
\hline Emosi Kanak-kanak & 0.688 & 0.000 \\
\hline
\end{tabular}

\section{Faktor ibu bapa memberi kesan ke atas perkembangan emosi kanak-kanak}

Keputusan Ujian ANOVA menunjukkan faktor ibu bapa adalah signifikan terhadap perkembangan emosi kanak-kanak $[\mathrm{F}(1,98)=88.164, \mathrm{p}<0.05]$. Bagi ujian regresi menunjukkan faktor ibu bapa mempunyai hubungan yang signifikan terhadap perkembangan emosi kanak-kanak. Faktor-faktor ini menerangkan $68.8 \%$ daripada varians perkembangan emosi kanak-kanak. Nilai $\mathrm{R}^{2}=0.474$ menunjukkan bahawa $47.4 \%$ perubahan dalam perkembangan emosi kanak-kanak disebabkan oleh perubahan faktor ibu bapa. Dapatan ini disokong oleh Aminah (2009) di mana ibu bapa mempengaruhi perkembangan emosi kanak-kanak. Dalam konteks ini institusi kekeluargaan memainkan peranan yang penting dalam memastikan perkembangan emosi kanak-kanak terpelihara. Bahkan, keluarga menjadi model ekspresi emosi kepada kanak-kanak (Casiddy, Parke \& Braungart, 1992; Cummings \& Davies, 1994; Denham et al., 1990; Dunn, 1995 dan Dunn \& Munn, 1987) dan jelas pemahaman mereka tentang emosi ini ada hubungannya dengan bagaimana ibu bapa itu mengekspresikan emosi mereka (Cassidy et al, 1992; Garner et al., 1997). 
Jadual 4: Faktor ibu bapa memberi kesan ke atas perkembangan emosi kanak-kanak

\begin{tabular}{|c|c|c|c|c|c|}
\hline \multirow[b]{2}{*}{ Model } & \multicolumn{2}{|c|}{ Unstandardized Coefficients } & \multirow{2}{*}{$\begin{array}{l}\text { Standardized } \\
\text { Coefficients } \\
\text { Beta }\end{array}$} & \multirow[t]{2}{*}{$\mathbf{T}$} & \multirow[t]{2}{*}{ Sig. } \\
\hline & B & Std. Error & & & \\
\hline 1 (Constant) & 2.580 & 0.239 & & 10.782 & 0.000 \\
\hline Faktor Ibu Bapa & 0.472 & 0.050 & 0.688 & 9.390 & 0.000 \\
\hline
\end{tabular}

\section{Kesimpulan}

Penglibatan ibu bapa penting bagi membantu perkembangan menyeluruh kanak-kanak di samping memperkembangkan keyakinan diri mereka dalam apa sahaja aktiviti yang dilakukan oleh mereka. Ibu bapa merupakan sokongan yang secara langsung memberikan kesan positif kepada perkembangan anak-anak. Dalam usaha meningkatkan perkembangan awal kanak-kanak, ianya tidak tertumpu kepada peranan ibu bapa sahaja di mana semua pihak seperti guru, masyarakat turut sama terlibat untuk memastikan kanak-kanak membesar dalam persekitaran yang baik. Oleh itu, semua pihak harus menggembleng tenaga dapat memastikan pembelajaran dan perkembangan kanak-kanak secara holistik tercapai dan seterusnya berupaya melahirkan generasi yang berminda kelas pertama.

\section{Rujukan}

Abdul Munir, Saharizah Salleh \& Misnan Jemali. (2016). Analisis Bentuk Didikan IbuBapa Bagi Membentuk Sahsiah Cemerlang: Kajian Di Sekolah Menengah Kebangsaan Pulau Sebang, Alor Gajah, Melaka. Jurnal Sains Sosial dan Kemanusiaan, 8(2):1-10.

Ainsworth. (2008). A Psychological Study Of The Strange Situation. Patterns Of Attachment.

Amin, Aizan S., Jamiah Manap, \& Noremy Md Akhir. (2016). Peranan Keluarga Dalam Kehidupan Kanak-Kanak Kurang Upaya Malaysia The Role Of Family In The Lives Of Disabled Malaysian Children. Akademika, 86(1), 21-30.

B, R. (2014). Apprenticeship In Thinking. The New York.

Baumrind. (1967). Effects Of Authoritative On Child Behavior", Child Development, .

Bhutto, N.A., Narejo, R.A., Butt, F., Shaikh A.S., \& Virwani, R. (2011, January). Parents' Perception Regarding Children Education. Kertas Kerja Dibentangkan Di $1^{\text {st }}$ International Conference Of Business Management, University Of Management And Technology.

Cassidy, J., Parke, R. D., Butkovsky, L., \& Braungart, J. M. (1992). Family-Peer Connections: The Roles Of Emotional Expressiveness Within The Family And Children's Understanding Of Emotions. Child Development, 63(3), 603-618.

Chao. (1994). Beyond Parental Control, Authoritarian Parenting Style: Understanding Chinese Parenting Through Performance In Chinese Children"e, . Child Development,.

Cherry, K. (2015). What They Are And Why They Matters. . Parenting Style.

Ciarrochi, J., Chan, A.Y.C, \& Bajgar, J. (2000). Measuring Emotional Intelligence In Adolescents. Personality And Individual Differences, 31, 1105-1119.

Cummings, E. M., Davies, P. T., \& Simpson, K. S. (1994). Marital Conflict, Gender, And Children's Appraisals And Coping Efficacy As Mediators Of Child Adjustment. Journal Of Family Psychology, 8(2), 141.

Darling, N. (1999). Parenting Style And Its Correlates. Eric Digest.

Denham, S. A., \& Holt, R. W. (1993). Preschoolers' Likability As Cause Or Consequence Of Their Social Behavior. Developmental Psychology, 29(2), 271.

Dodge, K. A., Pettit, G. S., \& Bates, J. E. (1994). Socialization Mediators Of The Relation Between Socioeconomic Status And Child Conduct Problems. Child Development, 65(2), 649-665.

Dunn, J., Bretherton, I., \& Munn, P. (1987). Conversations About Feeling States Between Mothers And Their Young Children. Developmental Psychology, 23(1), 132. 
Dunn, R., Griggs, S. A., Olson, J., Beasley, M., \& Gorman, B. S. (1995). A Meta-Analytic Validation Of The Dunn And Dunn Model Of Learning-Style Preferences. The Journal Of Educational Research, 88(6), 353-362.

Effa Rinny Octavia Paidin \& Abu Yazid Abu Bakar, 2019, Gaya Keibubapaan Mempengaruhi Emosi Dan Sikap Dalam Kalangan Pelajar Pintar Cerdas, International Counselling Seminar (Icons), Universiti Kebangsaan Malaysia.

Fagan, J. (2003). The Relationship Between Maternal Gatekeeping, Paternal Competence, Mothers' Attitudes About The Father Role, And Father Involvement. Journal Of Family Issue

Farrington. (2010). Family Influences On Delinquency.

Garner, D. M. (1997). Psychoeducational Principles In Treatment.

Glasgow. (1997). Parenting Styles, Adolescentse Attributions And Educational Outcomes In Nine Heterogeneous High Schoole",. Child Development, .

Gottfried. (1990). Maternal Employment, Family Environment And Children ${ }^{e ' S}$ Development: Infancy Through The School Years. Maternal Employment AndChildren's Development: Longitudinal Research, .

Gottfried. (1994). Maternal And Dual-Earner Employment, Status And Parenting.

Gottfried. (1999). Maternal And Dual-Earner Employment, Status And Parenting. Handbook $\quad$ Of Parenting.

Green, C. L.-D. (2007). Parents' Motivations For Involvement In Children's Education : AnEmpirical Test Of A Theoretical Model Of Parental Involvement. Journal Of Educational Psychology 99(3), 532-544

Hoover-Dempsey, K.V. \& Sandler, H.M. (1995). Parental Involvement In Children's Education: Why Does It Make A Difference?. Teachers College Record, 97(2), 311-331.

Kocayoruk, E. (2012). The Perception Of Parents And Well-Being Of Adolescents: Link With Basic Psychological Need Satisfaction. Procedia Social And Behavioral Sciences, 46, 3624-3628.

Kohn, M. (1969). Class And Conformity: A Study In Values,. University Of Chicago.

Lavasani, M.G., Afzali, L., \& Hejazi, E. (2011). The Relationship Between PerceivedParenting Styles, Social Support With Psychological Well-Being. Procedia Social And Behavioral Sciences, 15, 1852-1856.

Lerner, J. (1985). Maternal Role Satisfaction, Mother-Child Interaction And A Child Temperament, A Process Model.

Maccoby. (1983). Socialization In The Context Of Family. Parent-Child Interaction.

Martinez. (2007). Parenting Styles And Adolescents" Self-Esteem In Brazil.

Mcloyd, V. C. (1990). The Impact Of Economic Hardship On Black Families And Children: Psychological Distress, Parenting, And Socioemotional Development. Child Development, 61(2), 311-346.

Mh, B. (2011). Responsive And Cognitive Develoment In Children. Maternal Responsive. Mohamad Albaree Abdul \& Hazhari Ismail \& Iylia Mohmad \& Zaharah Osman, 2019, Perkembangan Emosi Kanak-Kanak Menggunakan Kaedah Pengajaran Berasaskan Aktiviti Muzik, Jurnal Pendidikan Awal Kanak-Kanak Kebangsaan, Universiti Sultan Idris.

Mortimer. (1979). Work Experience And Occupational Value Socialisation. A Longitudinal Study. American Journal Of Sociology.

Naimah, N., Dan, R., Yusri, M., Abstrak, M., Kunci, K., Tekanan, :, Keluarga, S., \& Daya, T. (2018). Tekanan Dalam Keluarga: Faktor-Faktor, Kesan Dan Strategi Daya Tindak Menangani Tekanan Family Stress: The Factors, Effects And Coping Strategies In Dealing With The Stress. Journal Of Human Development And Communication, 7(July 2018), 135-142.

Norly Jamil. (2010). Tingkah Laku Emosi Kanak-Kanak Dan Eksperesi Emosi Ibu Bapa. Proceeding Of The $4^{\text {th }}$ International Conference On Teacher Education: Join Conference Upi \& Upsi Bandung Indonesia. Fakulti Sains Kognitif Dan Pembangunan Manusia. Universiti Pendidikan Sultan Idris.

Nurul Aini Binti Omar \& Siti Marziah Zakaria. (2018). Hubungan Di Antara Gaya Keibubapaan Dan Kecerdasan Emosi Denga Masalah Tingkah Laku Kanak-Kanak. Fakulti Sains Sosial \& Kemanusiaan. Universti Kebangsaan Malaysia.

Patricia Anak Janting \& Norhayati Mohd Nor. (2017). Penglibatan Ibu Bapa Dalam Pendidikan Perkembanagn Awal Kanak-Kanak Di Zon Batang Kedup Serian Sarawak. Seminar Penyelidikan Pendidikan 2017. Universiti Kebangsaan Malaysia. 
Rieffe, C., Oosterveld, P., Miers, A.C., Terwogt, M.M., \& Ly, V. (2008). Emotion Awareness And Internalising Symptoms In Children And Adolescents: The Emotion Awareness Questionnaire Revised. Personality And Individual Differences, 45, 756-761.

Sailor, D. H. (2004). Supporting Children In Their Home, School, And Community. Boston: Allyn And Bacon.

Saiti, A. \& Mitrosili, E. Parental Perception Of The Education Of Their Adolescent Children: Evidence From Greek Secondary Education. Journal Of Career And Technical Education, 22 (1).

Shahida Hassim \& Chua Chu Tee \& Rosadah Abdul Majid \& Zalizan Mohd Jelas \& Hamizatun Akmal Md Yusof, 2012, Perembangan Kecerdasan Emosi Kanak Kanak Prasekolah Bermasalah Pendengaran : Implikasinya Terhadap Penglibatan Ibu Bapa, Akademika 82(2):137-142

Suhaiza Shuib. (2015). Perkembangan Sosio Emosi.Http://Www.Slideshare.Net/Suhaizashuib1

/Perkembangan-Sosio-Emosi-14413903

Tiller, A.E., Garrison, B.M.E., Block, E.B., Cramer, K., \& Tiller, V. (2013). Parenting Styles And Child Behavior In African American Families Of Preschool Children. Journal Of Clinical \& Child Adolescent Psychology, 31(2):272-277. 